\title{
INFORMATION SOURCES SUPPORTING INNOVATION IN THE PUBLIC SECTOR: THE CASE OF KOSOVO
}

\author{
Rinor F. Kurteshi \\ Department of Management and Informatics, Faculty of Economics, University of Prishtina \\ "Hasan Prishtina", Prishtina, Kosovo \\ rkurtesh@hawk.iit.edu
}

\begin{abstract}
This research looks at the main information sources supporting innovation in the public sector of Kosovo. This study is exploratory and a mixed methodology is used, while the findings are compared and contrasted with the current literature in the field of public sector innovation. Findings clearly indicate that visits to conferences, followed by ideas from management and examples of best practices by other governments were fundamental information sources supporting innovation in the public sector of Kosovo. Another important information source supporting innovation is the use of domestic sources of information and rarely information sources supporting innovation from events or organizations in European Union countries. Although, authors point out that gaining experience from public sector institutions in developed countries contributes in driving or supporting public sector innovation. In spite of that, public sector managers in Kosovo have failed to engage citizens or service users as information sources supporting innovation. The most recent literature provides evidence that citizens or service users knowledge and creativity is of paramount importance in enriching innovation. Henceforth, it is a prerequisite for public sector managers in Kosovo to be aware of the importance of co-creating and co-innovating with its service users. Conclusively, this study is a unique contribution to Kosovo's academics, administration practitioners and public policy makers.
\end{abstract}

Keywords: Public sector innovation, information sources supporting innovation, innovation culture, Kosovo.

JEL classification: $\mathrm{H} 11, \mathrm{M} 14, \mathrm{O} 31$.

\section{Introduction}

Innovation is crucial in today's environment. It is not of importance to organizations only, rather, it is of great importance to economies at large (Kallio et al., 2013). Moreover, innovation not only increases the capabilities of private organizations to remain competitive in the global market, nevertheless, it is of prime importance to today's public sector excessively (Goyal and Pitt, 2007; Bason, 2013).

European governments are acknowledging the prerequisite for innovation within the public sector, they require more productivity with fewer resources and continuously promote to foster creation of more public values and better response to new challenges. Governments worldwide are under pressure to reduce costs and become more efficient due to lack of resources, while demand for public services is increasing.

In the sphere of public sector innovation, open innovation and networked governance have gained the interest of both, academics and practitioners. According to the idea of open innovation, the innovation process should not be narrowly organized rather it should be facilitated in open settings with external actors (Lee et al., 2012). When firms focus internally, they have a tendency to miss a number of opportunities that we find outside the firm (Chesbrough, 2003). Open innovation is to go beyond the technocratic e-government 
paradigm. Open innovation focuses on external collaboration and innovation between citizens and public administration by offering new ways of citizen integration and participation in innovation (Munksgaard et al., 2012). Open innovation in the public sector realm tends to integrate the knowledge and experience of customers, users and external performers into the innovation and value creation process. Open innovation uses internal and external sources for collecting information (Munksgaard et al., 2012; Ghezzi et al., 2014).

In networked governance, the role of innovation is diversified and flexible. It is rather a bottom-up and user-driven way of incorporating innovation through social participation and by combining local resources for offering better services (Hasu et al., 2011). Co-innovation and user-driven services have been acknowledged to impact positively the innovativeness of organizations (Alam and Perry, 2002; Blazevic and Lieven, 2008). In networked governances, the users are the innovators themselves (Sundbo and Toivonen 2011; Brand, 2005).

Addressing the issue of public sector innovation is imperative, especially in transitional countries like Kosovo. Supporting innovation in the public sector enables achieving economic advantages, poverty reduction, harmony and institutional stability (Batalli, 2011). In Kosovo, the problem of poverty is evident, institutional stability is only an idea and economic growth is stagnant. The importance of addressing this problem is mandatory. Since this research is part of a larger study, the focus of this research is on identifying the information sources supporting innovation in the public sector of Kosovo.

The research objectives for analyzing the query are:

- O1. Discover the main information sources supporting innovation in the public sector of Kosovo.

- O2. Compare and contrast the information sources supporting innovation in the public sector of Kosovo, with the existing literature.

\section{Literature review}

\subsection{Public sector innovation}

Public sector organizations around the globe are becoming aware of the importance that innovation has in reaching effectiveness and efficiency in their daily activities. The importance of being innovative is occurring due to the rapid changes that are happening in the environment they perform, which is becoming complex and unified. Population in western economies is aging, economic growth is declining, service needs are growing due to shifts in population etc. (Kallio, 2013; Steen, 2009). These factors have reasoned the need of the public sector to innovate, to go outside its boundaries through collaborating with internal partners and external service-users for developing a more effective and efficient administration and to offer better service delivery (Bloch and Bugge, 2013).

To understand public sector innovation, in particular, we have to consider previous attempts that have been made to reinvent the public sector. New Public Management (NPM) is one of the initiatives, which emphasized the need of using private sector tools for achieving better outcomes. NPM is about transforming the public sector into result-oriented and transparent entity (Noordhoek and Saner, 2005; Hartley, 2005). Although NPM and public sector innovation have similarities, innovation initiatives do not highlight using private sector techniques. Innovation considers any idea, from any of the internal or external users that aim to improve the public sector in general. NPM was oriented in giving public sector managers the room and space to achieve their objectives but neglected employees and independent parties such as service-users. The innovation movement is oriented in giving all employee's as well as external parties the freedom to be critical and express new ideas but for this to 
happen, the culture and structure of the public sector must adapt to this new initiative (O'Byrne et al., 2014).

Networked government is another public sector initiative, which is aimed to reform the public sector. The idea of networked government is about improving performance by engaging multiple governmental organizations to work together on addressing particular problems and finding solutions to these problems (Yusoff, 2005). Networked government is associated with recognizing complex issues, which the public sector may face. Issues may be such as terrorism and globalization, and networked government faces these issues through coordinating activities and use of expertise from multiple governments. There is a link between networked government and public sector innovation whereby both indicate that the actual methods for managing the public sector are not satisfactory (Steen, 2009; Scott, 2010).

With the notion of public sector innovation, continuous improvement is also perceived as a driver of innovation in the public sector. The difference is that continuous improvement is about identifying areas where improvement can be made, while leaving behind the consequences of decisions derived (Liu, 2008). Continuous innovation is about reducing waste, reducing costs, improving performance and customer satisfaction (Fryer et al., 2007). Whereas innovation goes beyond: it is about developing a complete new product, service or process, by emphasizing that everyone needs to be innovative and that all have the responsibility and freedom to explore and criticize (Moore, 2005; Hartley, 2005; Borins, 2001).

\subsection{Open innovation and networked governance}

Open innovation has gained growing importance in the field of management (Ghezzi et al., 2014). The notion open innovation has been first used by Chesbrough (2003) and has since gained tremendous attention from both practitioners and researchers. The intense changes in dynamic markets characterized by outsourcing, networking and specialized technical knowledge have led to growing interest in open innovation (Durst and Stahle, 2014). However, open innovation only recently has received interest in the public sector domain and is also considered as a foster of innovation (Lakomaa and Kallberg, 2013; Fuglsang, 2008; Feller et al., 2008).

The idea of open innovation is to structure a business model by which innovation potential is converted into economic value. The innovation process should not be narrowly organized, rather it should be facilitated in open settings with external actors (Munksgard et al., 2012; Lee et al., 2012). When firms focus internally, they have a tendency to miss a number of opportunities that we find outside the firm (Chesbrough, 2003). As for the public sector, they are encouraged to capture the benefits of open innovation (such as getting involved, identifying demand, exploring incentive, co-creating, and encouraging entrepreneurship). Open innovation in the public sector realm tends to integrate the knowledge and experience of customers, users, and external performers into the innovation and value creation process. Open innovation uses internal and external sources for collecting information (Munksgaard et al., 2012; Ghezzi et al., 2014).

Hilgers and Ihl (2010) have derived to three dimensions by applying the concept of open innovation in the public sector realm:

1. Citizen Ideation and Innovation: This first tier focuses on engaging citizens in public sector innovation and ideation processes. It focuses on the knowledge and creativity within the citizenry for enhancing the quality of the common good.

2. Collaborative Administration: The second tier addresses the integration of citizens in advancing public administration processes. The objectives are to enhance the speed and responsiveness on issues of concern to the citizens and to reduce cost and increase quality. 
3. Collaborative Democracy: This level contemplates ways of improving public participation in improving policy processes.

Open innovation is often linked to the notion of citizen sourcing, which describes the design and configuration of a new relationship between the government and its people based on practices known to the private sector (Terwiesch and $\mathrm{Xu}, 2008$ ). However, until now, innovation activities in the public sector have long relied on stiff sector specific, top-down mechanisms, rather than flexible and empowered bottom-up practices (Carstensen and Bason, 2012). Gradually, both citizens and employees have become active in public sector innovation (Hasu et al., 2011; Bessant and Maher, 2009; Hartley, 2005).

Regarding networked governance, a shift from a 'bureaucratic' model of governance to 'networked governance' has happened (Hartley, 2005). Botero et al. (2012) have stated that there are changes taking place in how the role of citizens in society is experienced - in terms of how they feel responsible for things happening - and also in what is expected from them. In networked governance, the role of innovation is diversified and flexible. It is rather a bottom-up and user-driven way of incorporating innovation through social participation and by combining local resources for offering better services (Hasu et al., 2011). Co-innovation and user-driven services have been acknowledged to impact positively on the innovativeness of organizations (Alam and Perry, 2002; Blazevic and Lieven, 2008). In networked governances, the users are the innovators themselves (Sundbo and Toivonen 2011; Brand, 2005). Therefore, networks are considered a natural source of innovation. The proliferation of interactive form of governance through networks is important in enhancing public innovation (Sorensen and Torfing, 2011).

\section{Methodology}

For this study, a mixed methodology is utilized. Mixed methods are a convergence of quantitative and qualitative methods (Driscoll et al., 2007). To achieve the objectives set in this paper, two methods of collecting primary data are used. In principle, there is a structured survey questionnaire, the "Innobarometer 2010" developed by "The Gallup Organization", and an open-ended questionnaire for the interviewing part, which is derived from the "Innobarometer 2010". The Innobarmeter brings the attention of the public on a regular basis, by a series of publications regarding innovation (Onisor, 2012). The Innobarometer questionnaire was the most applicable one since it is related directly with the research objectives. Some minor changes have been made in order to adapt it to the specific objectives of the study.

The structure of the sample includes the central government, local governments and public corporations. The questionnaire was distributed to 52 public sector managers ranging from middle and top-level managerial positions and 8 interviews with public sector managers were successfully completed in accordance with the criteria set to achieve a balance between the methods and to achieve a more comprehensive view of the findings. The study is piloted in Kosovo.

Table 1: Participation of public institutions, according to activities

\begin{tabular}{|l|l|}
\hline Activities & Distribution \\
\hline General government activities or finance & $15.40 \%$ \\
\hline Education & $15.40 \%$ \\
\hline Social services & $25 \%$ \\
\hline Health & $5.80 \%$ \\
\hline Other & $34.60 \%$ \\
\hline [Refusal] & $3.80 \%$ \\
\hline TOTAL & $100 \%$ \\
\hline
\end{tabular}

Author's calculations based on data extracted from the distribution of questionnaires 
Regarding the sampling procedure and data collection, this study is based on convenient factors (contact details) and snowball sampling strategy (networks).

Due to the area of research, the analysis is mainly descriptive which relates to other studies in this area. Based on the methodological approach, data is analysed through comparison between both types of measurement tools, whereby the quantitative analysis offers a statistical view while the qualitative analysis provides a more exploratory understanding of the topic under research.

\section{Data Analysis and Findings}

The major sources of information that played an important role in developing innovation in the public sector domain were: Examples of best practices by other governments $(23 \%)$, ideas from management (35\%), and visits to conferences (42\%). Examples from other professional organizations also played an important role in fostering innovation (33\%).

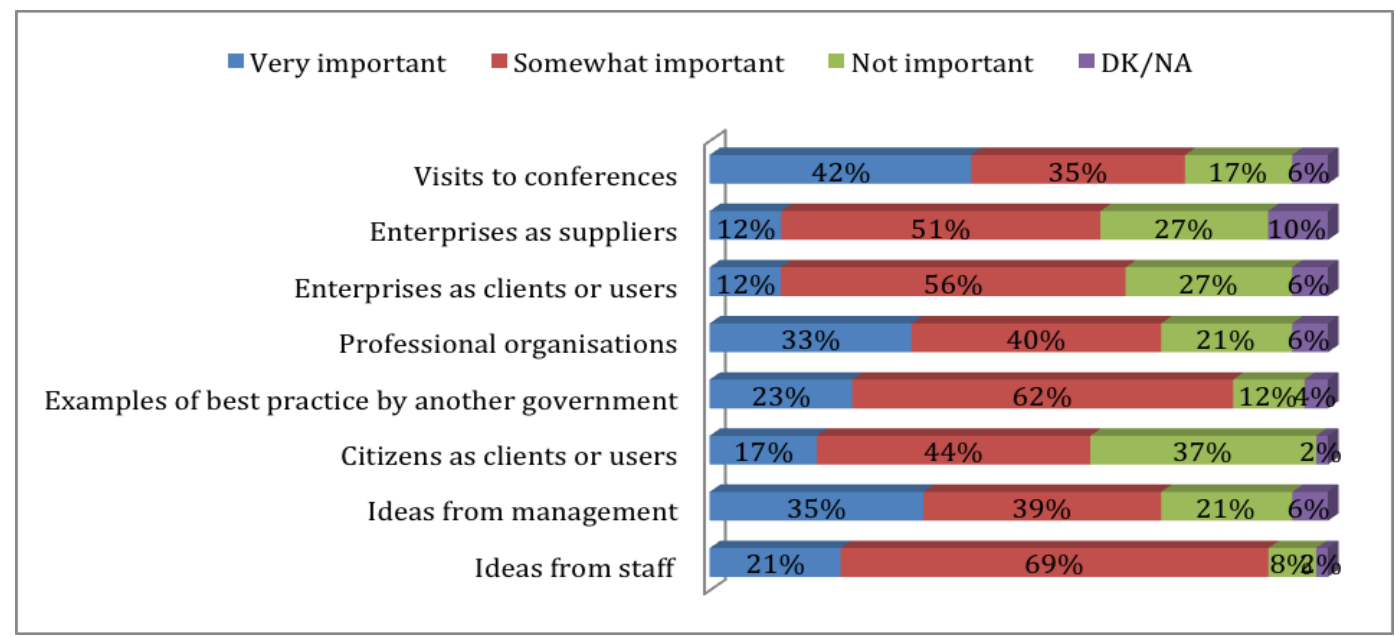

Figure 1: Importance of information sources for development of innovation

Source: Author's calculations based on data extracted from the distribution of questionnaires

Citizens as clients or users were significantly less likely to have had an important role as a source of information for developing innovation (whereby $37 \%$ said that it was not important as a source of developing innovation). Enterprises as clients or users were also among the least often noted sources of information for innovation development (27\% did not obtain any relevant information related to innovation from this source). Concerning the average importance in developing innovations, ideas from staff were more important than ideas coming from management (staff: 69\%, management: 39\%).

Regarding the qualitative data analysis, public sector managers in general have stated that "visits to conferences, examples of best practices by other governments and support from external experts or professional organizations" have been essential in supporting innovation. Interviewee P6 states: "The best way to originate to new solutions for solving specific problems is to gain experience from European Union countries or from countries in the region, by organizing specific conferences, by training our employees to become more innovative in their working environment after their return", whereas interviewee P4 supports the statement above by saying that "they continuously compare their current condition of innovation with examples of best practices by other governments in the region and governments in European Union countries, and thus evaluate their current condition of 
innovation and derive to specific solutions for specific problems." Another important source of information for supporting innovation is "ideas from management". All interviewees have stated that they have regular meetings where they discuss about specific problems and share ideas on how to approach the problems identified. Nevertheless, they also indicate that their employees have the dedicated space and time to share ideas in supporting innovation, however they point out that their employees are not motivated and not used to this culture of co-creating and co-innovating. In addition to that, although employees have the space and time, the management in most of the cases does not take their ideas seriously. Therefore, it can be concluded that all eight interviewees consider "visits to conferences" and "benchmarking with other organizations" as main sources of information supporting innovation. The qualitative and quantitative findings regarding sources of information are in line.

While considering the scope of activities: local, regional and national level public sector institutions tend to draw information from visits to conferences (which was the most predominant source of information for innovation, with $35 \%$ in the local scope, $47 \%$ in the regional level and $67 \%$ in the national level).

Table 2: Very important sources of information supporting innovation, \% by organizational background

\begin{tabular}{|c|c|c|c|c|c|c|c|c|}
\hline & 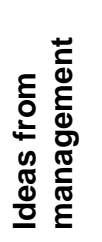 & 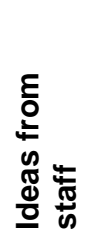 & 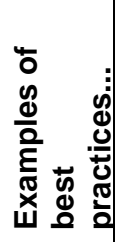 & 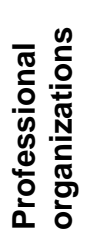 & 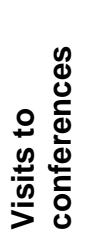 & 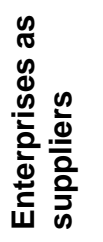 & 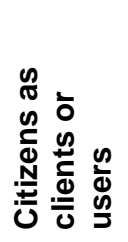 & 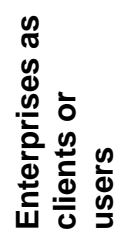 \\
\hline \multicolumn{9}{|l|}{$\begin{array}{c}\text { Size } \\
\text { (employees) }\end{array}$} \\
\hline Less than 10 & 40 & 0 & 20 & 0 & 60 & 0 & 0 & 0 \\
\hline $10-49$ & 40.9 & 28.6 & 23.8 & 47.6 & 42.9 & 4.8 & 33.3 & 14.3 \\
\hline $50-99$ & 37.5 & 25 & 25 & 25 & 50 & 12.5 & 12.5 & 12.5 \\
\hline $100-249$ & 11.1 & 11.1 & 33.3 & 22.2 & 33.3 & 22.2 & 0 & 11.1 \\
\hline $250-499$ & 16.7 & 16.7 & 16.7 & 50 & 50 & 16.7 & 16.7 & 16.7 \\
\hline $500-999$ & 50 & 50 & 0 & 0 & 0 & 50 & 0 & 0 \\
\hline 1000 or more & 100 & 0 & 0 & 0 & 0 & 0 & 0 & 0 \\
\hline \multicolumn{9}{|l|}{$\begin{array}{c}\text { Geographic } \\
\text { areas }\end{array}$} \\
\hline Local & 34.5 & 24.1 & 24.1 & 37.9 & 34.5 & 10.3 & 20.7 & 13.8 \\
\hline Regional & 17.6 & 17.6 & 17.6 & 29.4 & 47.1 & 17.6 & 17.6 & 11.8 \\
\hline National & 83.3 & 16.7 & 33.3 & 16.7 & 66.7 & 0 & 0 & 0 \\
\hline \multicolumn{9}{|l|}{ Sector } \\
\hline $\begin{array}{l}\text { General gov't } \\
\text { activities }\end{array}$ & 12.5 & 25 & 37.5 & 50 & 50 & 25 & 25 & 25 \\
\hline Education & 37.5 & 25 & 25 & 50 & 75 & 0 & 12.5 & 12.5 \\
\hline Health & 33.3 & 33.3 & 33.3 & 33.3 & 33.3 & 66.7 & 15.4 & 33.3 \\
\hline Social services & 38.5 & 23.1 & 7.7 & 23.1 & 15.4 & 0 & 33.3 & 0 \\
\hline Other & 38.9 & 5.6 & 22.2 & 22.2 & 44.4 & 11.1 & 16.7 & 11.1 \\
\hline
\end{tabular}

Source: Author's calculations based on data extracted from the distribution of questionnaires

Regarding the use of international sources to obtain information for innovation purposes we see that innovators predominantly used domestic sources of information (50\%), which is 
also indicated from interviewee P5, who states: "The most dominant source of information for developing innovations are trainings and conferences organized in Kosovo, and rarely outside of Kosovo". The next source of information was events organized in European Union countries $(19 \%)$, while only $(10 \%)$ of respondents indicated that they have obtained information essential to innovations from organizations or events organized outside the European Union.

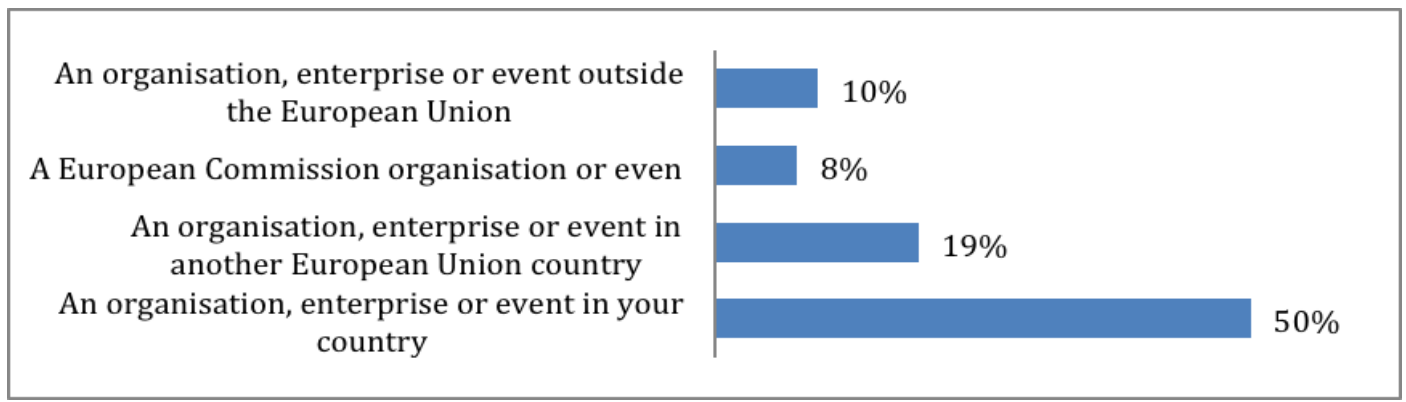

Figure 2: Source of information to innovations

Source: Author's calculations based on data extracted from the distribution of questionnaires

\section{Discussion and Conclusions}

Data analysis indicates that visits to conferences, followed by ideas from management and examples of best practices by other governments were the fundamental sources that supported innovation. These information sources supporting innovation are strongly supported by the literature. Borins (2011) indicates that employees have to be actively engaged in innovation by continuously learning from external events regarding public sector innovation. In addition, ideas from management and benchmarking are very important in supporting innovation. Fernanderz and Rainey (2006) state that top-management has a crucial role in achieving a successful alternation from a risk averse culture to an inclusive culture, which accepts novel ideas from everyone. Public sector managers influence the outcomes of an organization (Damanpour and Schneider, 2006). As for the comparison of performance against benchmarks, it is of paramount position in gaining useful information concerning the weaknesses and strengths of an organization (Garvin et al., 2008). Therefore, these information sources are acknowledged from the literature and from the findings as important in supporting innovation.

However, the public sector of Kosovo has failed in engaging citizens as information sources for supporting innovation. The most recent literature provides evidence that citizens or service users knowledge and creativity is of great importance in enhancing innovation. According to the literature, the public sector has to incorporate the knowledge and experience of customers, users and external performers into the innovation and value creation process (Munksgaard et al., 2012; Ghezzi et al., 2014; Hilgers and Ihl, 2010). Therefore, it is a prerequisite for public sector managers in Kosovo to be aware of the importance of co-creating and co-innovating with its service users.

Regarding the use of international sources of information for supporting innovation, the public sector of Kosovo in general uses domestic sources of information supporting innovation and rarely obtains information from events or organizations in European Union countries. Although, the literature considers international sources of information as important in driving innovation in the public sector. 


\section{Recommendations}

Based on the analysis, the following recommendations are directed to Kosovar policy makers, public sector managers and administration practitioners. Based on the literature, co-creating and co-innovating with service users is found to be very important in driving innovation (Kallio et al., 2013). However, Kosovo's public sector has not provided any particular result in this area. Therefore, it is recommended to acknowledge the importance of service-users in the process of developing and implementing public sector innovations. Another mutable recommendation is to pursue international events, which would enrich and extend their current knowledge and expertise concerning public sector innovation. Domestic sources of information were found to be the most widespread information source supporting innovation. Moreover, ideas from staff aren't taken seriously, therefore, it is recommended for public sector managers and public policy analysts to work on creating a culture of innovation that emphasizes co-creating and co-innovation with internal and external sources of information for supporting innovation. Nonetheless, these recommendations should be tackled strategically, since developing a culture of innovation is a lifetime process, which requires continuous commitment. Finally, researchers and public policy analysts from developing countries should identify alternative ways to gain experience from developed countries regarding public sector innovation.

\section{Limitation of the study}

Access to information was one of the limitations faced under the topic of research. In addition, the concept of public sector innovation posed a new definition to some of the interviewees, thus the concept had to be explained thoroughly. A significant limitation to the study was the use of mixed methods. Public sector managers in Kosovo hesitated to participate in the study and deliver information regarding their experience with innovation, especially during the interview process, which had to be recorded. However, clarifying to participants the purpose of the study solved this drawback and by providing them with a consent form, which strictly acknowledged their right that the information provided would remain confidential and only used for study purposes. Moreover, utilizing mixed methods was time consuming and costly.

\section{References}

Alam, I. and C. Perry., 2002. A Customer-oriented New Service Development Process. Journal of Services Marketing, 16 (6), pp. 515-534.

Bason, CH., 2013. Design-led innovation in government. Stanford Social Innovation Review, 11 (2), pp. 15-17.

Batalli, M., 2011. Impact of Public Administration Innovations on Enhancing the Citizens' Expectations. International Journal of e-Education, e-Business, e-Management and e-Learning, 1 (2), pp. 156-162.

Bessant, J. and L. Maher., 2009. Developing Radical Service Innovations in Healthcare the Role of Design Methods. International Journal of Innovation Management, 13(4), pp. 555-568.

Blazevic, V. and A. Lievens., 2008. Managing Innovation Through Customer Coproduced Knowledge in Electronic Services: An Exploratory Study. Journal of the Academy of Marketing Science, 36 (1), pp. 138-151.

Bloch, C., and Bugge, M., 2013. Public sector innovation - From theory to measurement. Structural Change and Economic Dynamics, 27, pp. 133-145. 
Borins, S., 2001. Encouraging innovation in the public sector. Journal of Intellectual Capital, 2 (3), pp. 310-319.

Botero, A., Paterson, A. and Saad-Sulonen, J., 2012. Towards Peer-production in Public Services: cases from Finland. Helsinki, Finland: Aalto University.

Brand, R., 2005. The Citizen-innovator. The Innovation Journal: The Public Sector Innovation Journal, 10 (1), pp. 1-10.

Carstensen, H. V., and Bason, C., 2012. Powering collaborative policy innovation: Can innovation labs help. The Innovation Journal: The Public Sector Innovation Journal, 17 (1), pp. 1-26.

Chesbrough, H., 2003. Open Innovation: The New Imperative for Creating and Profiting from Technology. Boston, MA: Harvard Business School Press.

Damanpour, F. and Schneider, M., 2006. Phases of the adoption of innovation in organizations: Effects of environment, organization and top Managers. British Journal of Management, 17 (3), pp. 215-236.

Driscoll, D.L., Yeboah, A.A., Salib,P. and Rupert, D.J., 2007. Merging qualitative and quantitative data in mixed methods research: How to and why not. Ecological and Environmental Anthropology, 3 (1), pp. 19-28.

Durst, S. and Stahle, P., 2014. Success Factors of Open Innovation-A Literature Review. International Journal of Business Research and Management, 4 (4), pp, 111-130.

Feller, J., Finnegang, P. and Nilsson O., 2008. Open innovation and public administration: transformational typologies and business model impacts. European Journal of Information Systems, 20 (3), pp. 358-374.

Fernandez, S. and Rainey, H.G., 2006. Managing Successful Organizational Change in the Public Sector. Public administration review, 66 (2), pp. 168-176.

Fryer, K.J., Antony, J. and Douglas, A., 2007. Critical success factors of continuous improvement in the public sector. The TQM Magazine, 19 (5), pp. 497-517.

Fuglsang, L., 2008. Capturing the benefits of open innovation in public innovation: a case study. International Journal of Services Technology and Management, 9 (3-4), pp. 234-248. Garvin, D.A., Edmondson, A. and Gino, F., 2008. Is Yours a Learning Organization. Harvard Business Review, 86 (3), pp. 109-116.

Ghezzi, A., Balocco, R. and Rangone, A., 2014. The relationship between Open Innovation and Strategy: data-driven analysis of the Mobile Value Services Industry. In System Sciences (HICSS), 2014 47th Hawaii International Conference on System Science, pp. 1073-1082.

Goyal, S. and Pitt, M., 2007. Determining the role of innovation management in facilities management. Facilities, 25 (1/2), pp. 48-60.

Hartley, J., 2005. Innovation in Governance and Public Services: Past and Present. Public Money and Management, 25 (1), pp. 27-34.

Hasu, M., E. Saari and T. Mattelmäki., 2011. Bringing the Employee Back: Integrating User Driven and Employee-Driven Innovation in the Public Sector. User-based Innovation in Services, pp. 251-278.

Hilgers, D. and Ihl, C., 2010. Citizensourcing: Applying the Concept of Open Innovation to the Public Sector. The International Association for Public Participation, 4 (1), pp. 68-88.

Kallio, K., Lappalainen, I. and Tammela, K., 2013. Co-innovation in public services: Planning or experimenting with users. The Innovation Journal: The Public Sector Innovation Journal, 18 (3), pp. 1-16.

Lakomaa, E. and Kallberg, J., 2013. Open Data as a Foundation for Innovation: The Enabling Effect of Free Public Sector Information for Entrepreneurs. Digital Object Identifier, 1 (2169-3536), pp. 558-562.

Lee, S., Hwang, T. and Choi, D., 2012. Open innovation in the public sector of leading countries. Management Decision, 50 (1), pp. 147-162. 
Liu, M., 2008. Arizona's experience in continuous improvement. Policy \& Practice, 66 (2), pp. $42-42$.

Moore, M.H., 2005. Break-through innovations and continuous improvement: Two different models of innovation processes in the public sector. Public Money \& Management, 25, pp. 43-50.

Munksgaard, K.B., Evald, M.R., Clarke, A.H. and Nielsen, S.L., 2012. Open Innovation in Public-Private Partnerships. Ledelse and Erhvervsokonomi, 77 (2), pp. 41-51.

Noordhoek, P. and Saner R., 2005. Beyond new public management: Answering the claims of both politics and society. Public Organization Review, 5 (1), pp. 35-53.

O'Byrne, L, Miller, M, Douse, C, Venkatesh, R, \& Kapucu, N., 2014. Social Innovation in the Public Sector: The Case of Seoul Metropolitan Government. Journal Of Economic \& Social Studies (JECOSS), 4 (1), pp. 53-71.

Onisor, L., 2012. Marketing and Innovation: Young people's attitude towards new products. Annals of The University of Oradea, Economic Science Series, 21 (1), pp. 1179-1186.

Scott, M., 2010. Understanding E-Government Implementation from an NPM Strategic Reform Perspective. Communications of the Association for Information Systems, 27, pp. 493-516.

Sorensen, E. and Torfing, J., 2011. Enhancing Collaborative Innovation in the Public Sector. Administration and Society, 43 (8), pp. 842-868.

Steen, V.B., 2009. Measuring innovation in the BC public sector: developing a performance measurement framework for IGRS'innovation program. Unpublished MA dissertation.

Sundbo, J. and M. Toivonen., 2011. User-based Innovation in Services. Edward Elgar Publishing.

Terwiesch, C. and $\mathrm{Xu}, \mathrm{Y} ., 2008$. Innovation contests, open innovation, and multiagent problem solving. Management science, 54 (9), pp. 1529-1543.

Yusoff, M., 2005. CAPAM Symposium on Networked Governance: The public service as a learning organization: the Malaysian experience. International Institute of Administrative Sciences, 71 (3), pp. 463-474.

\section{Bio-note}

Rinor F. Kurteshi is a teaching assistant in the Department of Management and Informatics, Faculty of Economics, University of Prishtina "Hasan Prishtina", Prishtina in Kosovo. He holds an MSc degree in Management from The University of Sheffield and an MPA degree from Illinois Institute of Technology. His research interests include public sector innovation, public finance and organizational behavior. 